\title{
ANALISIS CUSTOMER VALUE PADA PERANCANGAN APLIKASI E-PROCUREMENT DI PT INDESSO AROMA
}

\author{
Henkie Ongowarsito \\ Information Systems Department, School of Information Systems, Binus University \\ Jl. K.H. Syahdan No. 9, Palmerah, Jakarta Barat 11480 \\ henkie@binus.edu
}

\begin{abstract}
More online business applications are utilized by companies; one of which is e-procurement. PT Indesso Aroma as a manufacturing company of essential oils, natural extracts, and aromatic chemicals products needs to improve its conventional procurement process to e-procurement to be more effective and efficient. For that, a research is conducted towards the performance and interest of the company's procurement system. Furthermore, the current SAP system application support is developed, as the customer values are analyzed using gap analysis to see the benefits of its application for the company. The e-procurement design uses OOAD method with UML diagram notation including analysis of problem domain, application domain, architectural design and component design. Cost-benefit analysis is performed to see an increase in customer value from the e-procurement application based on measurements of NPV, IRR and ROI of investing in the e-procurement design. Thus an e-procurement application is created that is expected to improve the company's procurement process with several key features such as Purchase requisition, Purchase Order, Purchase Return, Supplier Catalog and Supplier Quotation.
\end{abstract}

Keywords: e-procurement, gap analysis, OOAD, cost benefit analysis, customer value

\begin{abstract}
ABSTRAK
Aplikasi bisnis online semakin banyak dimanfaatkan oleh perusahaan, salah satunya yaitu eprocurement. PT Indesso Aroma sebagai perusahaan manufaktur produk essential oils, natural extracts, dan aromatic chemicals ingin memperbaiki proses pengadaan barangnya yang masih konvensional menggunakan eprocurement agar lebih efektif dan efisien. Untuk itu, dilakukan penelitian terhadap kinerja dan kepentingan sistem procurement di perusahaan tersebut. Selanjutnya, aplikasi pendukung sistem SAP saat ini dikembangkan, dan customer value dianalisis menggunakan analisis gap untuk melihat manfaat aplikasinya bagi perusahaan. Perancangan e-procurement menggunakan metode OOAD dengan notasi UML diagram yang meliputi analisis problem domain, application domain, architectural design dan component design. Analisis biaya-manfaat (cost benefit analysis) digunakan untuk melihat peningkatan customer value dari aplikasi e-procurement berdasarkan pengukuran NPV, IRR dan ROI dari investasi dalam perancangan e-procurement ini. Sehingga dihasilkan suatu aplikasi e-procurement yang dapat meningkatkan efektivitas pengadaan barang dengan beberapa fitur utama seperti Purchase Requisition, Purchase Order, Purchase Return, Supplier Catalog dan Supplier Quotation.
\end{abstract}

Kata kunci: e-procurement, analisis gap, OOAD, cost benefit analysis, customer value. 


\section{PENDAHULUAN}

Perkembangan ilmu pengetahuan dan teknologi semakin pesat setiap saat. Seiring dengan adanya perkembangan ilmu pengetahuan dan teknologi tersebut, Perusahaan dituntut untuk dapat mengikutinya, terutama agar tidak kalah dengan pesaingnya. Penggunaan internet dalam bisnis juga semakin banyak dimanfaatkan oleh perusahaan. Salah satu bagian dari $e$-business yaitu $e$-procurement (electronic procurement) yang semakin banyak diminati oleh perusahaan.

PT Indesso didirikan di Purwokerto, Jawa Tengah pada tahun 1968 oleh Robert H. Gunawan. Perusahaan ini merupakan anak perusahaan dari PT Indesso Primatama. PT Indesso Aroma bergerak dibidang manufacturing, dan juga merangkap sebagai trader untuk industri-industri besar. Pusat kegiatan pengadaan barang dalam PT Indesso Aroma terletak di Plant (pabrik) yang dimilikinya, yaitu di Cileungsi dan Purwokerto. PT Indesso Aroma sebagai salah satu perusahaan yang bergerak di bidang manufaktur dalam produk essential oils, natural extracts, dan aromatic chemicals ingin memperbaiki proses pengadaan barangnya, dari proses pengadaan barang secara konvensional agar menjadi lebih efektif dan efisien dengan menggunakan e-procurement.

Untuk mengatasi masalah-masalah seperti pemberian penawaran dari pemasok, dalam hal ini vendor-vendor yang ada, masih dilakukan dengan proses konvensional, yaitu melalui email, faks dan penawaran langsung dari vendor dengan cara mengirimkan perwakilan vendor untuk memberikan penawaran bagi perusahaan. Tidak semua pemasok saat ini bekerja sama dengan PT Indesso Aroma sehingga sering terjadi maverick purchasing. Selain itu, barang yang dibeli dari supplier tersebut belum tentu sesuai dengan kriteria kualitas dari PT Indesso Aroma sehingga membutuhkan proses yang lebih lama untuk pengecekan kualitas barang. Maka dari itu, perusahaan ingin mengembangkan suatu sistem yang dapat membantu dalam proses pengadaan barang, yaitu sistem e-procurement yang dapat mendukung sistem SAP yang sudah berjalan saat ini.

Kalakota dan Robinson (2001, p.314) mendefinisikan Procurement sebagai semua aktivitas perusahaan yang melibatkan proses mendapatkan barang-barang dari pemasok; hal ini meliputi pembelian, dan kegiatan logistik seperti transportasi, penerimaan dan penyimpanan barang di gudang sebelum barang tersebut digunakan. Menurut Chafey (2004), e-procurement (electronic procurement) adalah integrasi elektronik dan pengelolaan semua kegiatan pengadaan, termasuk permintaan pembelian, otorisasi, pemesanan, pengiriman dan pembayaran antara pembeli dan pemasok.

Menurut Remenyi et al (2007, p.180), Gap terjadi karena adanya perbedaan antara ekspektasi dan kinerja sesungguhnya yang terjadi. Gap bernilai positif jika kinerja yang dicapai melebihi ekspektasi, sedangkan Gap yang bernilai positif jika sebaliknya, kinerja yang dicapai dibawah ekspektasi, yang mengindikasikan perlunya peningkatan kinerja. Analisis Gap juga dapat digunakan untuk penerapan automasi dalam sistem dan pengukurannya menggunakan bantuan kuisioner yang dibagi menjadi beberapa bagian untuk mengukur atribut/kriteria yang penting bagi efektivitas dari sistem dan bagian selanjutnya untuk mengukur kinerja dari sistem informasi yang ada berdasarkan atribut/kriteria yang sama.

Maka dari itu penelitian bertujuan mempelajari kinerja dan kepentingan sistem procurement yang berjalan di PT Indesso Aroma; mengembangkan aplikasi e-procurement sebagai aplikasi pendukung yang mendukung penggunaan SAP di PT Indesso Aroma dan melakukan analisis Customer Value terhadap aplikasi pendukung untuk melihat manfaat pengembangan e-procurement bagi perusahaan.

Dengan adanya penerapan e-procurement diharapkan dapat meningkatkan efisiensi dan efektivitas, baik dari segi biaya dan waktu di dalam proses pengadaan barang dari pemasok, agar 
proses pengadaan barang lebih transparan dan mengurangi terjadinya masalah dalam proses pengadaan barang dan memberikan keunggulan kompetitif bagi PT Indesso Aroma dibandingkan dengan perusahaan pesaingnya. Manfaat bagi Pemasok adalah dapat menghemat waktu untuk memberikan penawaran, karena penawaran dapat diberikan melalui sistem e-procurement secara online, bagi pemasok yang ingin bekerja sama dengan PT Indesso dapat berhubungan dengan PT Indesso secara lebih mudah dan membantu pemasok untuk dapat mengetahui informasi kebutuhan barang dari PT Indesso secara lebih cepat.

\section{METODE}

Metode yang digunakan dalam perancangan e-procurement ini adalah Object Oriented Analysis and Design (OOAD) dengan notasi UML diagram yang meliputi analisis problem domain, application domain, architectural design dan component design. OOOAD berusaha untuk menggabungkan data dan proses menjadi suatu gagasan tunggal yang disebut objects. OOAD memperkenalkan object diagram yang mendokumentasikan sistem dipandang dari segi objects dan interaksinya (Whitten et al, 2001, p.97).

Analisis biaya-manfaat (cost benefit analysis) digunakan untuk melihat peningkatan customer value dari aplikasi e-procurement. Menurut Watkins, cost-benefit analysis (CBA) mengestimasi dan menghitung total nilai uang setara dengan manfaat dan biaya untuk menentukan sejauh mana manfaatnya. Sedangkan Block et al (2009:195), mendefinisikan analisis biaya \& manfaat sebagai perbandingan antara biaya dan manfaat yang mungkin didapat oleh perusahaan. Adapun metode yang dapat digunakan untuk pengukuran analisis biaya dan manfaat adalah ROI, IRR dan NPV. Perhitungan ROI yang sering digunakan adalah "simple ROI" dengan rumusan:

$$
\text { Simple ROI }=\frac{\text { Gains }- \text { Investment Costs }}{\text { Investment Costs }} \times 100 \%
$$

Perhitungan IRR menggunakan rumusan sebagai berikut (Gitman, 2006, p.425):

$$
0=\sum_{i=1}^{n} \frac{C F_{t}}{(1+I R)^{2}}-C F_{0}
$$

Perhitungan NPV menggunakan rumusan berikut (Remenyi et al, 2007:324):

$$
N P V=\sum_{\text {Present value of benefit }=\frac{\text { Benefit }}{(1+i)^{2}}}
$$

dimana $i=$ tingkat diskonto dari cost of capital.

\section{HASIL DAN PEMBAHASAN}

\section{Analisis Sistem Berjalan}

Aktivitas primer yang dijalankan di PT Indesso Aroma sebagai berikut: (1) inbound logistic berupa pengambilan bahan baku dari Plant I ke Plant II dan sebaliknya, pengajuan Purchase Requisition (PR) pada saat membutuhkan bahan baku untuk produksi, penyimpanan bahan baku yang dibeli ke dalam gudang, dan pengecekan kualitas bahan baku yang digunakan dalam proses produksi; 
(2) operation, berupa kegiatan produksi untuk menghasilkan produk PT Indesso Aroma, pengecekan terhadap kualitas hasil produksi, dan penjadwalan dan pengecekan terhadap ketersediaan bahan baku untuk proses produksi; (3) outbond logistic, berupa penyimpanan barang produksi di dalam gudang PT Indesso Aroma, dan pengiriman produk dari gudang PT Indesso kepada pelanggan (konsumen); (4) pemasaran dan penjualan, berupa promosi produk melalui pameran-pameran bahan pangan untuk produk bumbu dan ekstrak alam, penawaran kepada konsumen - dalam hal ini biasanya konsumen adalah perusahaan atau industri lain, negosiasi dan kesepakatan kerjasama dengan konsumen, dan pemberitahuan kepada konsumen jika ada penawaran khusus (promo khusus); (5) pelayanan (services), berupa pengiriman pesanan konsumen tepat waktu, penerimaan laporan kerusakan produk dari konsumen, dan pemberian penggantian jika terjadi kerusakan barang produksi kepada konsumen PT Indesso Aroma.

Selain aktivitas primer PT Indesso Aroma juga melakukan beberapa aktivitas pendukung pelaksanaan proses bisnisnya.

Pertama adalah firm infrastructure - infrastruktur yang mendukung perusahaan dalam menjalankan proses bisnisnya terdiri dari: (a) struktur organisasi yang jelas dimana keputusan strategik bagi perusahaan diambil oleh Presiden Director dan semua Vice President dan Director bertanggug jawab kepada Presiden Director; (b) pengelolaan keungan ditangani oleh departemen Finance, sedangkan pemeriksaan laporan keuangan dan pajak perusahaan di bawah departemen Accounting \& Tax. Untuk audit diserahkan kepada Departemen System \& Audit; (c) pengelolaan kegiatan operasional kantor dilakukan oleh departemen General Affair \& Facility Maintanance.

Aktivitas pendukung berikutnya adalah human resource management. Departemen Human Resources dalam perusahaan melakukan aktivitas sebagai berikut: (1) perekrutan dan pemberhentian karyawan sesuai kebutuhan perusahaan; (2) evaluasi dan penilaian kinerja karyawan; (3) memastikan karyawan di PI Indesso mendapatkan hak dan memenuhi kewajibannya.

Aktivitas pendukung ketiga dilakukan oleh Technology Department, di antaranya: (1) pengelolaan dan pengembangan sistem SAP yang diterapkan di perusahaan oleh Departemen SAP; (2) pengelolaan dan pengembangan teknologi lain (misalnya pengembangan mesin yang digunakan dalam produksi) yang diterapkan oleh perusahaan dilakukan oleh Departemen IT; (3) penelitian dan pengembangan produk baru dan peningkatan kualitas dalam produknya dilakukan oleh Departemen Research \& Development.

Aktivitas pendukung terakhir yaitu procurement. Kegiatan yang dilakukan dalam proses pengadaan barang di PT Indesso Aroma sebagai berikut: (1) mengelola permintaan barang dari tiap divisi dalam bentuk Purchase Requisition (PR); (2) menerima dan mengumpulkan penawaran (supplier quotation) yang diberikan oleh pemasok; (3) memilih pemasok yang sesuai untuk memenuhi kebutuhan dari PT Indesso akan bahan baku dan kebutuhan lainnya; (4) melakukan negosiasi dan kunjungan kepada calon pemasok maupun pemasok bagi PT Indesso Aroma; (5) berhubungan dengan calon pemasok dan melakukan kunjungan kepada calon pemasok; (6) memberikan kuisioner kepada calon pemasok yang ingin menjadi pemasok di PT Indesso Aroma. Secara singkat aktivitas primer dan aktivitas pendukung perusahaan terangkum pada Gambar 1. 


\begin{tabular}{|c|c|c|}
\hline \multicolumn{3}{|c|}{ Firm Infrastructure } \\
Human Resource Management \\
Menjamin kelancaran proses bisnis, mencegah terjadinya penyelewengan tanggung jawab, menjamin SOP dalam perusahaan dapat terlaksana dengan baik \\
\hline \multicolumn{3}{|c|}{ Technology Department } \\
\hline \multicolumn{3}{|c|}{ Procurement } \\
\hline \multicolumn{3}{|c|}{ Memanfaatkan sistem yang terintegrasi untuk memudahkan kegiatan dalam perusahaan, memudahkan pengelolaan data dan informasi }
\end{tabular}

Gambar 1. Value chain PT Indesso Aroma.

Setelah dipelajari terdapat beberapa kelemahan dari sistem saat ini. Pertama, pengisian kuisioner untuk pemilihan calon vendor pemasok bisa memakan waktu cukup lama karena kuisioner masih dicetak dalam kertas dan dikirimkan secara konvensional, melalui surat, faks dan representatif dari perusahaan. Masalah muncul ketika kuisioner dari vendor membutuhkan waktu cukup lama untuk sampai ke PT Indesso Aroma sedangkan kebutuhan barang bagi perusahaan semakin mendesak untuk terpenuhi.

Kedua, pengiriman penawaran dari pemasok (Supplier Quotation) kepada PT Indesso Aroma masih menggunakan email, faks dan penawaran langsung dari vendor dengan cara mengirimkan perwakilan dari vendor (representatif).

Ketiga, terjadinya pembelian barang pada vendor baru yang belum pernah melakukan transaksi dengan PT Indesso Aroma dapat mengakibatkan barang yang dipesan tidak sesuai permintaan atau tidak dalam kondisi baik, sehingga hal ini dapat mengakibatkan biaya untuk proses retur barang dan juga pemborosan waktu untuk pengecekan kualitas barang.

Keempat, keterbatasan waktu akses SAP bagi tiap user dapat menjadi masalah ketika user sedang menginput data. Ketika ada waktu idle dari user, akses user tersebut dapat ditutup sebelum data selesai di-input. Hal ini menimbulkan keinginan dari perusahaan untuk membuat suatu aplikasi yang dapat mendukung penggunaan SAP.

Kelima, Ada tiga departemen yang terlibat dalam proses pengadaan barang. Masalah dapat terjadi ketika ada dua departemen atau lebih yang mendapat permintaan barang untuk keperluan produksi dan harus tersedia dalam waktu bersamaan, tetapi dari pemasok salah satu departemen dapat menyediakan secara lebih cepat, sehingga dapat menimbulkan biaya untuk penyimpanan bahan baku ataupun biaya bagi departemen lainnya untuk dapat menyediakan barang secara lebih cepat. Keenam, biaya yang ditimbulkan dari seringnya melakukan kunjungan kepada pemasok sangat besar bagi perusahaan.

Dari beberapa kelemahan yang terdapat pada PT Indesso Aroma saat ini, ada beberapa usulan yang disarankan untuk mengatasi masalah tersebut, yaitu: (1) pada saat melakukan registrasi dalam 
aplikasi e-procurement, vendor yang ingin menjadi pemasok bagi PT Indesso Aroma harus mendownload kuisioner dan mengisinya lalu meng-upload kembali kuisioner yang sudah terisi. Hal ini dapat membantu pengisian kuisioner agar lebih cepat; (2) dengan membuat aplikasi e-procurement, dalam bentuk portal pengadaan barang berbasis web, yang dapat membantu pemasok memberikan penawaran (Supplier Quotation) kepada perusahaan secara lebih cepat. Selain itu, dengan adanya Supplier Catalog, jika terdapat bahan bahan baru yang ingin ditawarkan oleh supplier, dapat dengan mudah diberikan melalui aplikasi e-procurement; (3) vendor yang ingin bekerja sama dengan PT Indesso dapat melakukan registrasi dan pengisian kuisioner. Dari kedua hal tersebut, perusahaan dapat menentukan layak atau tidaknya vendor bekerjasama dengan perusahaan; (4) aplikasi e-procurement dirancang untuk dapat membantu user, tapi untuk pembahasan lebih lanjut mengenai bagaimana aplikasi e-procurement ini berhubungan dengan SAP tidak dibahas dalam penyusunan artikel ini; (5) mengembangkan e-procurement sebagai portal bagi departemen yang terlibat dalam proses pengadaan barang, sehingga departemen yang terlibat dapat melihat permintaan dan penawaran barang sehingga dapat menentukan pemesanan yang terbaik bagi perusahaan untuk mengurangi biaya; (6) meminimalisir biaya untuk kunjungan dengan melakukan kerjasama dengan pemasok tetap di PT Indesso dan memberikan kepercayaan kepada pemasok tetapnya untuk memberikan penawaran melalui sistem e-procurement, sehingga biaya untuk kunjungan pada saat negosiasi dapat dikurangi.

Tabel 1 di bawah ini menunjukan gap yang terjadi dari perbedaan tingkat keinginan pemasok dengan kinerja saat ini dari sistem yang ada di perusahaan. Kolom ketiga menunjukan rata-rata jawaban responden untuk tingkat kepentingan, sedangkan kolom keempat menunjukan rata-rata jawaban responden untuk kinerja aktual saat ini.

Tabel 1

Gap antara Tingkat Kepentingan dengan Kinerja Aktual

\begin{tabular}{|c|c|c|c|c|c|}
\hline No & Kriteria (Indikator) & $\begin{array}{c}\text { Importance } \\
\text { (A) }\end{array}$ & $\begin{array}{c}\text { Actual } \\
\text { Performance } \\
\text { (B) } \\
\end{array}$ & GAP (A-B) & Rank \\
\hline 1 & $\begin{array}{l}\text { Estimasi permintaan barang dari PT } \\
\text { Indesso disampaikan dengan jelas. }\end{array}$ & 4.45 & 4.03 & 0.42 & 10 \\
\hline 2 & $\begin{array}{l}\text { Adanya permintaan barang secara } \\
\text { berkala. }\end{array}$ & 4.32 & 3.81 & 0.51 & 9 \\
\hline 3 & $\begin{array}{l}\text { Kemudahan memberikan penawaran } \\
\text { kepada PT Indesso Aroma }\end{array}$ & 4.52 & 3.77 & 0.75 & 5 \\
\hline 4 & $\begin{array}{l}\text { Adanya respon yang cepat dari PT } \\
\text { Indesso untuk menjawab penawaran } \\
\text { dari perusahaan Pemasok. }\end{array}$ & 4.61 & 3.71 & 0.9 & 3 \\
\hline 5 & $\begin{array}{l}\text { Proses transaksi secara terbuka, jelas } \\
\text { dan jujur }\end{array}$ & 4.35 & 4.26 & 0.09 & 11 \\
\hline 6 & $\begin{array}{l}\text { Sistem yang dapat mengotomatisasi } \\
\text { pemberian permintaan perusahaan }\end{array}$ & 3.77 & 3.1 & 0.67 & 7 \\
\hline 7 & $\begin{array}{l}\text { Sistem yang dapat mengurangi } \\
\text { kesalahan selama proses pembelian } \\
\text { barang }\end{array}$ & 4.39 & 3.32 & 1.07 & 1 \\
\hline 8 & $\begin{array}{l}\text { Aplikasi sistem yang dapat diakses } \\
\text { dengan mudah }\end{array}$ & 4.32 & 3.29 & 1.03 & 2 \\
\hline 9 & $\begin{array}{l}\text { Kemampuan sistem untuk } \\
\text { memperbaiki produktivitas }\end{array}$ & 3.9 & 3.26 & 0.64 & 8 \\
\hline 10 & $\begin{array}{l}\text { Efektivitas biaya dalam proses } \\
\text { transaksi }\end{array}$ & 4.1 & 3.39 & 0.71 & 6 \\
\hline
\end{tabular}




\begin{tabular}{llcccc}
\cline { 3 - 5 } 11 & $\begin{array}{l}\text { Aplikasi pendukung yang membantu } \\
\text { proses pengadaan barang }\end{array}$ & 4.19 & 3.29 & 0.9 & 3 \\
\hline 12 & $\begin{array}{l}\text { Aplikasi sistem pengadaan barang } \\
\text { yang mudah digunakan }\end{array}$ & 4.16 & 3.32 & 0.84 & 4 \\
\hline
\end{tabular}

\section{Rancangan Sistem yang Diusulkan}

Tabel 2 berikut menunjukkan solusi yang diusulkan dari analisis gap yang dilakukan.

Tabel 2

Fitur yang Dihasilkan dari Analisis Gap

\begin{tabular}{|c|c|c|c|c|}
\hline No & $\begin{array}{c}\text { Kriteria } \\
\text { (Indikator) }\end{array}$ & Gap & Solusi & Fitur \\
\hline 1 & $\begin{array}{l}\text { Estimasi } \\
\text { permintaan barang } \\
\text { dari PT Indesso } \\
\text { disampaikan } \\
\text { dengan jelas }\end{array}$ & $\begin{array}{l}\text { Selisih antara tingkat kepentingan dan } \\
\text { kinerja saat ini tidaklah terlalu besar } \\
\text { untuk kategori pemberian estimasi } \\
\text { permintaan barang sehingga menurut } \\
\text { pemasok, hal ini tidak menjadi } \\
\text { masalah dalam sistem. }\end{array}$ & $\begin{array}{l}\text { Terus meningkatkan performa } \\
\text { pelayanan dari PT Indesso dengan } \\
\text { menggunakan sistem saat ini dibantu } \\
\text { dengan adanya sistem baru, yaitu } e \text { - } \\
\text { procurement. }\end{array}$ & - \\
\hline 2 & $\begin{array}{l}\text { Adanya } \\
\text { permintaan akan } \\
\text { barang secara } \\
\text { berkala }\end{array}$ & $\begin{array}{l}\text { Permintaan barang dalam sistem saat } \\
\text { ini diberikan secara konvensional. } \\
\text { Dari SAP, Purchase Requisition harus } \\
\text { di print telebih dahulu, lalu membuat } \\
\text { surat PR kepada pemasok, hal ini } \\
\text { membutuhkan waktu yang lama, } \\
\text { sedangkan pemasok ingin permintaan } \\
\text { barang diberitahukan secara berkala } \\
\text { sehingga mudah bagi mereka untuk } \\
\text { memberikan penawaran dalam bentuk } \\
\text { SQ. }\end{array}$ & $\begin{array}{l}\text { Pada aplikasi e-procurement yang } \\
\text { dirancang, akan dibuat fitur bagi } \\
\text { pemasok untuk melihat permintaan } \\
\text { (PR) apa saja yang dikeluarkan oleh } \\
\text { perusahaan. Aplikasi yang dirancang } \\
\text { berbasis web yang bertujuan } \\
\text { memfasilitasi penggunanya, dalam hal } \\
\text { ini pemasok dan juga user untuk dapat } \\
\text { berkomunikasi secara lebih cepat dan } \\
\text { membantu dalam proses penyampaian } \\
\text { permintaan (PR) secara berkala. }\end{array}$ & $\begin{array}{l}\text { Purchase } \\
\text { Requisition }\end{array}$ \\
\hline 3 & $\begin{array}{l}\text { Kemudahan } \\
\text { memberikan } \\
\text { penawaran kepada } \\
\text { PT Indesso Aroma }\end{array}$ & $\begin{array}{l}\text { Pemasok menginginkan kemudahan } \\
\text { dalam memberikan penawaran kepada } \\
\text { PT Indesso Aroma sedangkan kinerja } \\
\text { saat ini belum memenuhi harapan } \\
\text { pemasok. }\end{array}$ & $\begin{array}{l}\text { Memberikan kemudahan kepada calon } \\
\text { pemasok yang ingin bekerja sama } \\
\text { dengan perusahaan dengan membuat } \\
\text { sistem e-procurement yang dapat } \\
\text { menerima registrasi calon pemasok } \\
\text { baru dan menghubungkannya dengan } \\
\text { database yang dapat menyimpan data } \\
\text { pemasoknya, selain itu pada aplikasi e- } \\
\text { procurement yang dirancang, } \\
\text { ditambahkan fitur "add SQ" untuk } \\
\text { menambahkan penawaran dari } \\
\text { pemasok }\end{array}$ & $\begin{array}{l}\text { Supplier } \\
\text { Quotation, } \\
\text { Supplier } \\
\text { Catalog }\end{array}$ \\
\hline 4 & $\begin{array}{l}\text { Adanya respon } \\
\text { yang cepat dari } \\
\text { PT Indesso untuk } \\
\text { menjawab } \\
\text { penawaran dari } \\
\text { perusahaan } \\
\text { Pemasok }\end{array}$ & $\begin{array}{l}\text { Penting bagi pemasok untuk mendapat } \\
\text { jawaban dari penawaran yang } \\
\text { diberikan secara cepat, dan sistem } \\
\text { diharapkan dapat memenuhi hal } \\
\text { tersebut sedangkan dari performa } \\
\text { sistem saat ini, masih ada dalam } \\
\text { kategori cukup dan belum baik. }\end{array}$ & $\begin{array}{l}\text { Fitur pada aplikasi e-procurement akan } \\
\text { ditambahkan bagi user departemen } \\
\text { Material dan Procurement untuk dapat } \\
\text { membuat PO (Purchase Order) dari } \\
\text { penawaran (SQ) yang diberikan oleh } \\
\text { pemasok. }\end{array}$ & $\begin{array}{l}\text { Purchase } \\
\text { Order }\end{array}$ \\
\hline 5 & $\begin{array}{l}\text { Proses transaksi } \\
\text { secara terbuka, } \\
\text { jelas dan jujur }\end{array}$ & $\begin{array}{l}\text { Saat ini proses transaksi tidak } \\
\text { mengalami selisih yang cukup besar } \\
\text { antara kepentingan dan kinerja aktual } \\
\text { yang terjadi. }\end{array}$ & $\begin{array}{l}\text { Karena selisih tidak terlalu besar dan } \\
\text { nilai yang didapat sudah cukup baik } \\
\text { maka tidak terlalu menjadi masalah } \\
\text { bagi perusahaan. Perusahaan hanya } \\
\text { perlu menjaga hubungan baik dengan } \\
\text { pemasoknya. }\end{array}$ & - \\
\hline 6 & $\begin{array}{l}\text { Sistem yang dapat } \\
\text { mengotomatisasi } \\
\text { pemberian }\end{array}$ & $\begin{array}{l}\text { Pada saat bahan yang dibutuhkan } \\
\text { habis, kebutuhan untuk dapat } \\
\text { berhubungan dengan pemasoknya dan }\end{array}$ & $\begin{array}{l}\text { Aplikasi e-procurement nantinya } \\
\text { dirancang untuk dapat dihubungkan } \\
\text { dengan sistem SAP agar dapat }\end{array}$ & - \\
\hline
\end{tabular}




\begin{tabular}{|c|c|c|c|c|}
\hline & $\begin{array}{l}\text { permintaan } \\
\text { perusahaan }\end{array}$ & $\begin{array}{l}\text { memberitahukan kehabisan barang } \\
\text { secara real time sangat penting, } \\
\text { namun hal itu belum dapat terpenuhi } \\
\text { dari sistem saat ini karena pengiriman } \\
\text { permintaan masih melalui email atau } \\
\text { faks atau surat. }\end{array}$ & $\begin{array}{l}\text { langsung menerima PR yang langsung } \\
\text { dibuat oleh sistem SAP dan } \\
\text { memberitahukan kepada pemasok } \\
\text { mengenai PR yang dibutuhkan melalui } \\
\text { aplikasi e-procurement tersebut. }\end{array}$ & \\
\hline 7 & $\begin{array}{l}\text { Sistem yang dapat } \\
\text { mengurangi } \\
\text { kesalahan selama } \\
\text { proses pembelian } \\
\text { barang }\end{array}$ & $\begin{array}{l}\text { Penting agar sistem dapat mengurangi } \\
\text { kesalahan pada proses pembelian } \\
\text { barang, namun kinerja saat ini hanya } \\
\text { menunjukan tingkat cukup bagi sistem } \\
\text { yang ada untuk menangani kesalahan } \\
\text { yang terjadi }\end{array}$ & $\begin{array}{l}\text { Dengan membuat aplikasi berbasis } \\
\text { web yang dapat menyimpan cookies } \\
\text { dari user dan session sehingga pada } \\
\text { saat input data dapat langsung } \\
\text { menggunakan data cookie, yaitu data } \\
\text { yang disimpan pada komputer client, } \\
\text { dalam hal ini dalam browser. Session } \\
\text { mirip dengan cookie hanya saja jika } \\
\text { cookie ada di sisi client, session ada di } \\
\text { sisi server. Selain itu, mengadakan } \\
\text { integrasi dengan sistem SAP sebagai } \\
\text { tindakan lanjutan untuk mengurangi } \\
\text { kesalahan yang terjadi. }\end{array}$ & - \\
\hline 8 & $\begin{array}{l}\text { Kemampuan } \\
\text { sistem untuk } \\
\text { memperbaiki } \\
\text { produktivitas }\end{array}$ & $\begin{array}{l}\text { Kinerja sistem untuk memperbaiki } \\
\text { produktivitas menurut pemasok } \\
\text { berada pada kategori cukup sedangkan } \\
\text { dari segi kepentingan, hal ini dianggap } \\
\text { mendekati skala penting, sehingga } \\
\text { sebisa mungkin harus terpenuhi. }\end{array}$ & $\begin{array}{l}\text { Membuat aplikasi e-procurement } \\
\text { untuk mendukung sistem pengadaan } \\
\text { barang yang ada sekarang, peningkatan } \\
\text { manfaat yang didapat dapat dilihat dari } \\
\text { analisis customer value yang ada di } \\
\text { sub bab 4.3. }\end{array}$ & - \\
\hline 9 & $\begin{array}{l}\text { Efektivitas biaya } \\
\text { dalam proses } \\
\text { transaksi }\end{array}$ & $\begin{array}{l}\text { Menurut pemasok efektivitas biaya } \\
\text { adalah hal yang penting tetapi saat ini } \\
\text { masih dalam taraf cukup dan belum } \\
\text { baik. }\end{array}$ & $\begin{array}{l}\text { Aplikasi e-procurement dirancang } \\
\text { untuk dapat diakses secara online oleh } \\
\text { pemasok, sehingga dapat mengurangi } \\
\text { pengiriman penawaran secara } \\
\text { konvensional dan dapat menghemat } \\
\text { waktu bagi pemasok untuk dapat } \\
\text { melihat permintaan dari perusahaan. }\end{array}$ & - \\
\hline 10 & $\begin{array}{l}\text { Aplikasi } \\
\text { pendukung yang } \\
\text { membantu proses } \\
\text { pengadaan barang }\end{array}$ & $\begin{array}{l}\text { Adanya aplikasi yang mendukung } \\
\text { proses pengadaan barang adalah hal } \\
\text { yang penting namum kondisi saat ini } \\
\text { masih belum sesuai dengan harapan. }\end{array}$ & $\begin{array}{l}\text { Pembuatan sistem e-procurement yang } \\
\text { dapat membantu para calon pemasok } \\
\text { dari PT Indesso untuk berhubungan } \\
\text { dengan perusahaan secara lebih mudah } \\
\text { dan membantu dalam proses retur } \\
\text { barang kepada pemasok. }\end{array}$ & $\begin{array}{l}\text { Register, } \\
\text { Purchase } \\
\text { Return }\end{array}$ \\
\hline 11 & $\begin{array}{l}\text { Aplikasi sistem } \\
\text { pengadaan barang } \\
\text { yang mudah } \\
\text { digunakan }\end{array}$ & $\begin{array}{l}\text { Aplikasi yang sesuai dengan } \\
\text { keinginan pemasok dan mudah } \\
\text { digunakan belum dapat tercapai oleh } \\
\text { perusahaan }\end{array}$ & \multirow{2}{*}{$\begin{array}{l}\text { Membuat sistem e-procurement, dalam } \\
\text { bentuk portal pengadaan barang } \\
\text { berbasis web, yang dapat membantu } \\
\text { pemasok memberikan penawaran } \\
\text { kepada perusahaan secara lebih cepat } \\
\text { dan membantu perusahaan } \\
\text { memberikan permintaan kepada } \\
\text { pemasoknya. }\end{array}$} & - \\
\hline 12 & $\begin{array}{l}\text { Aplikasi sistem } \\
\text { yang dapat } \\
\text { diakses dengan } \\
\text { mudah }\end{array}$ & $\begin{array}{l}\text { Aplikasi yang mudah diakses juga } \\
\text { merupakan hal yang penting menurut } \\
\text { pemasok tetapi saat ini belum dapat } \\
\text { dipenuhi oleh sistem yang ada. }\end{array}$ & & - \\
\hline
\end{tabular}

Gambar 3 di bawah ini menunjukan hubungan antar class beserta hubungan multiplicities antar class. 


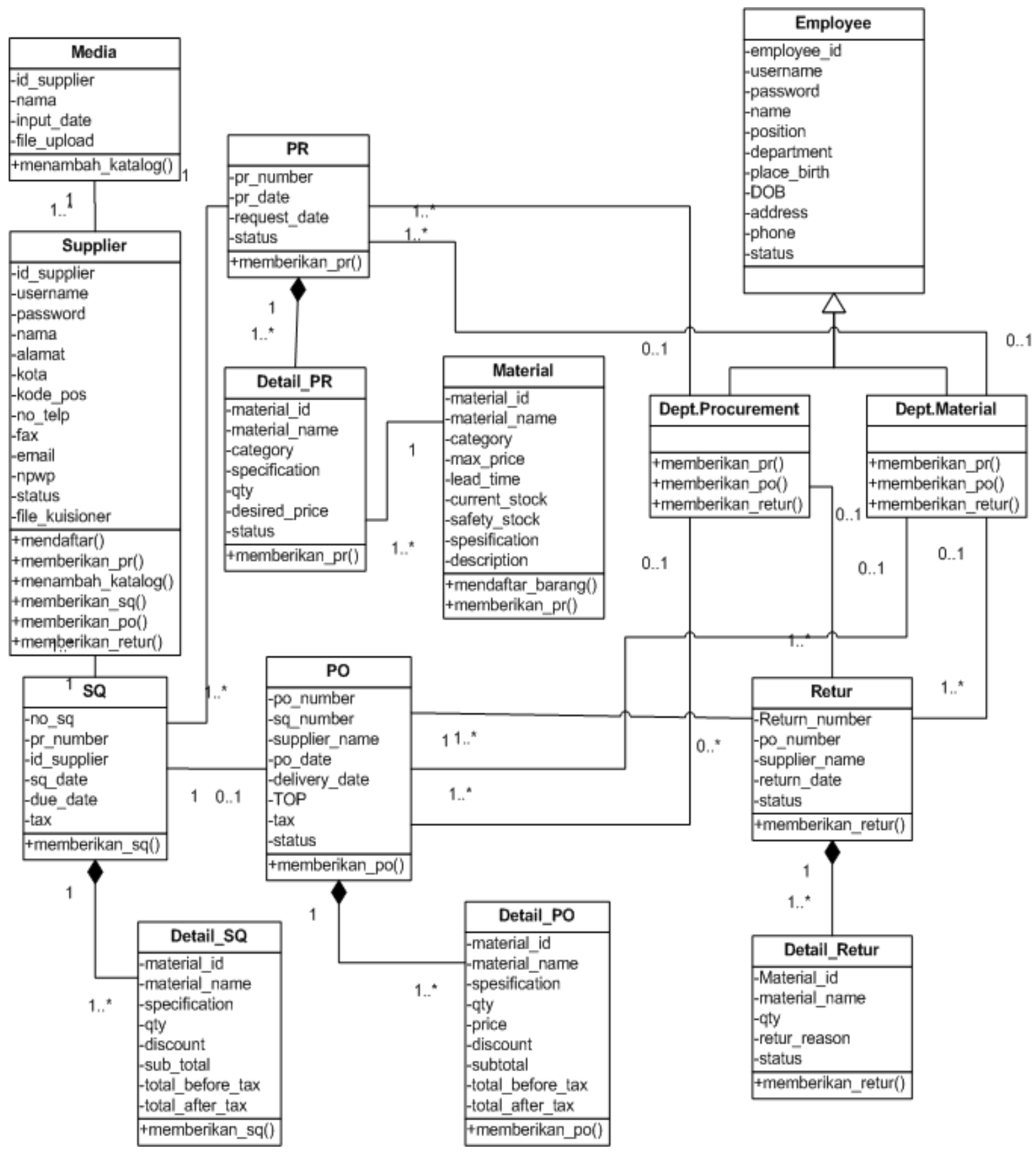

Gambar 3. Class Diagram.

Untuk melihat hubungan dari use case dan actor dalam sistem, dapat dilihat pada Gambar 4 di bawah ini. Dari pengumpulan data yang dilakukan, diperoleh rincian biaya pengembangan aplikasi pada Tabel 3. 


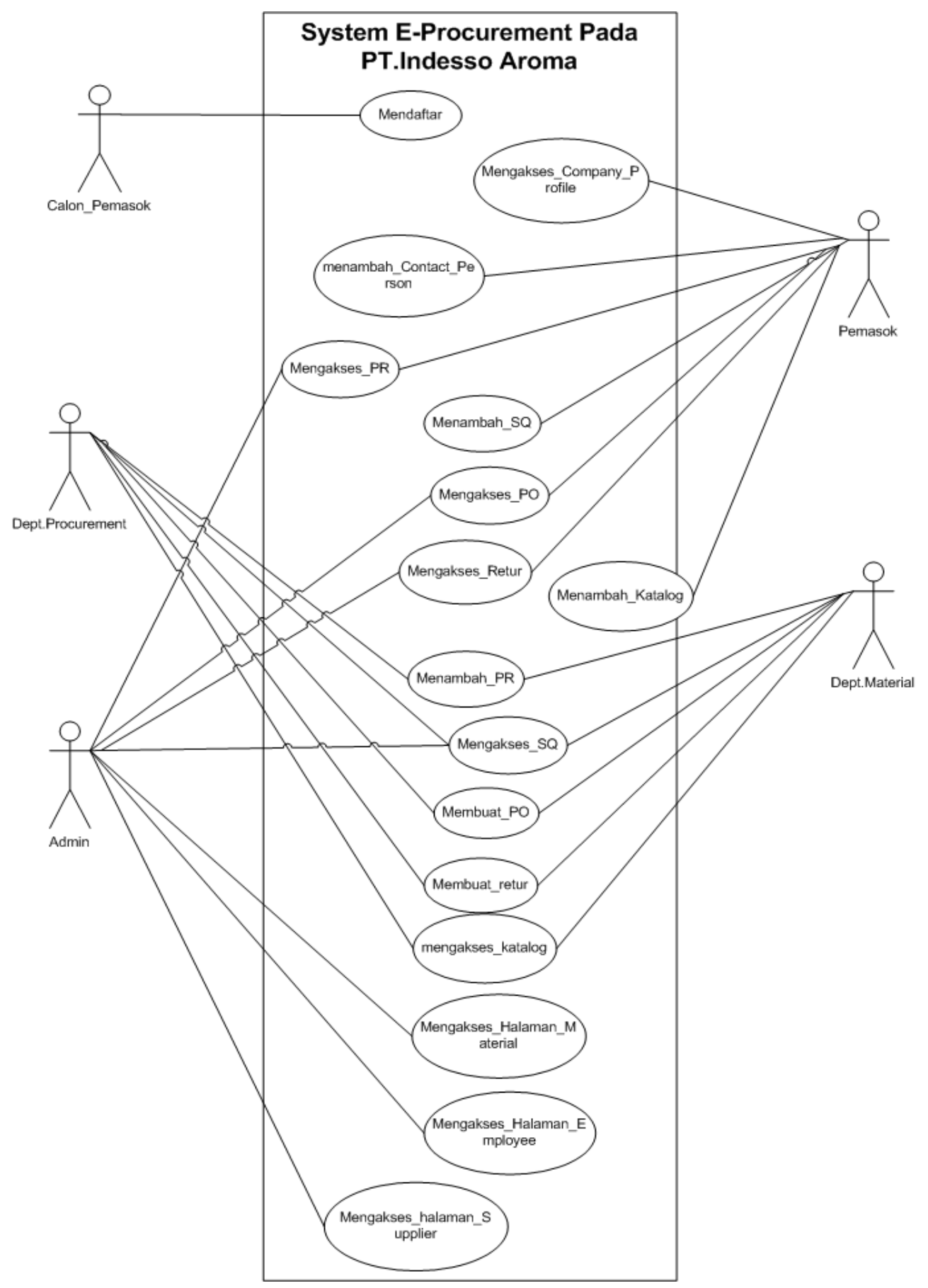

Gambar 4. Use Case Diagram. 
Tabel 3

Tabel Daftar Biaya

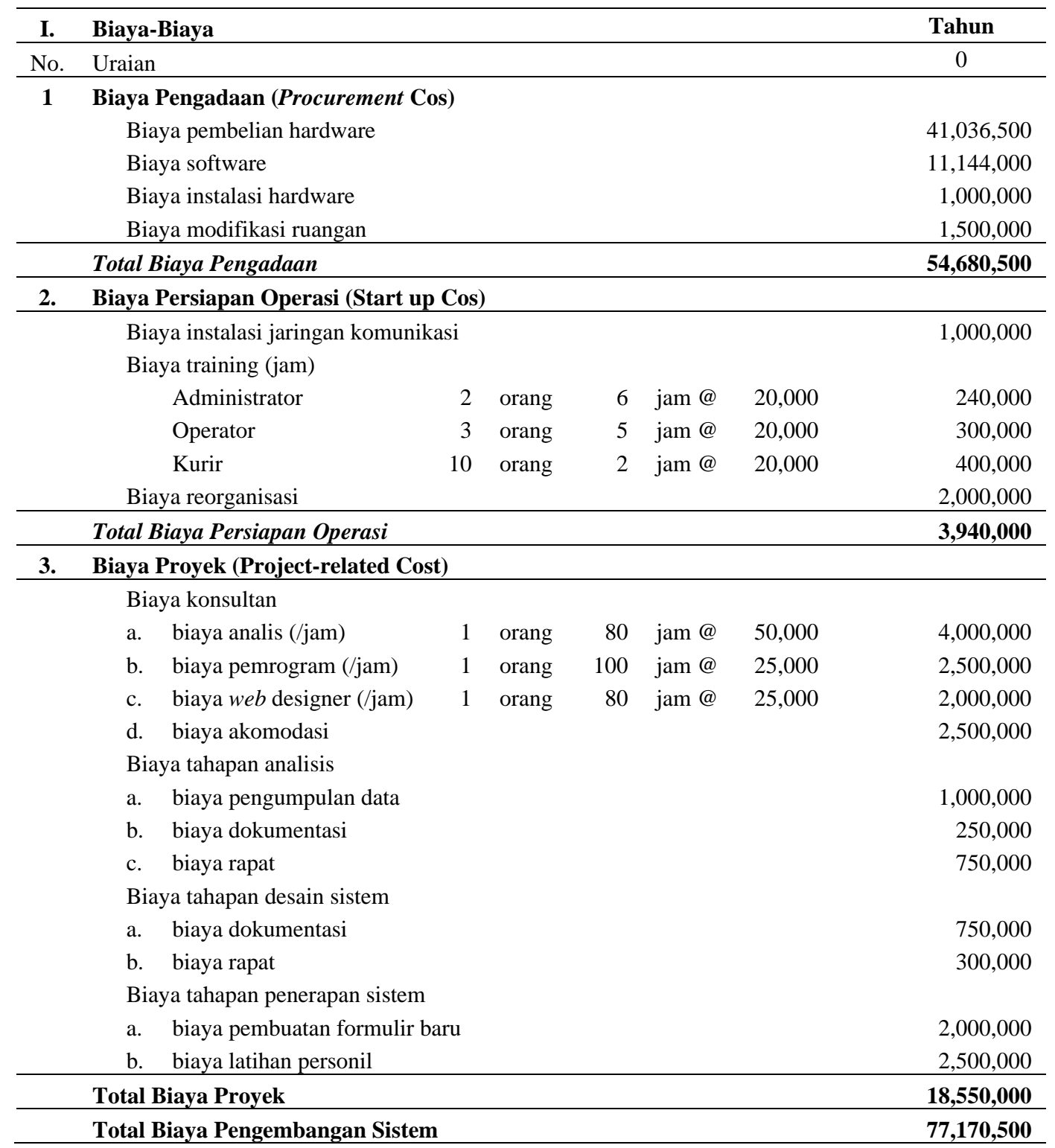

Data perkiraan manfaat yang bisa didapat dengan menggunakan e-procurement bagi PT Indesso Aroma dilihat dari sisi tangible benefit dapat dilihat pada Tabel 4 berikut:

Tabel 4

Tabel Perkiraan Daftar Manfaat

\section{MANFAAT-MANFAAT}

No Uraian

Tahun 0

1 Keuntungan berujud (tangible)

a. Pengurangan biaya penggunaan kertas

b. Pengurangan biaya sourcing

c. Peningkatan efektifitas produksi

d Pengurangan biaya visiting $50,000,000$

e Peningkatan kecepatan penemuan

$16,500,000$ 
Dari akumulasi data biaya dan manfaat di atas, dapat dihitung analisis biaya dan manfaat dengan menggunakan rumus NPV, IRR dan ROI dan mendapatkan hasil sebagai berikut (Tabel 5):

Tabel 5

Financial Analysis

\begin{tabular}{lc}
\hline Financial Analysis & Result \\
\hline ROI & 30.94381921 \\
NPV & 14693136.36 \\
IRR & 0.309438192 \\
\hline
\end{tabular}

Dari data di atas, dapat dilihat bahwa dari perhitungan yang dilakukan melalui analisis biaya dan manfaat menggunakan analisis keuangan berdasarkan ROI, NPV dan IRR, dapat diambil beberapa hasil sebagai berikut: (1) tingkat pengembalian untuk pembuatan sistem e-procurement ini bagi PT Indesso Aroma mencapai angka 30,94\%; (2) Net Present Value (NPV) yang didapat bernilai positif, dimana jika NPV bernilai positif maka proyek pembuatan aplikasi e-procurement ini dapat memberikan keuntungan bagi PT Indesso Aroma; (3) IRR yang didapat dari perhitungan menunjukan nilai positif dan mencapai nilai 0,309.

\section{PENUTUP}

Berdasarkan tujuan yang ingin dicapai dan menggunakan beberapa analisis untuk mencapai tujuan tersebut, dapat diambil simpulan sebagai berikut:

Pertama, pada saat mempelajari kinerja dan kepentingan dari sistem procurement di PT Indesso Aroma, masih ditemukan adanya gap (selisih) antara kinerja sistem saat ini dan tingkat kepentingan beberapa faktor yang diukur. Tingkat kepentingan disini sebagai harapan yang diinginkan oleh pemasok PT Indesso Aroma. Maka dari itu, diperlukan adanya aplikasi e-procurement untuk mendukung sistem yang ada pada proses pengadaan barang saat ini.

Kedua, dari analisis dan perancangan yang dilakukan dengan menggunakan OOAD, dihasilkan aplikasi e-procurement yang berbasis web dengan menggunakan bahasa pemrograman ASP.net dan aplikasi ini nantinya akan digunakan oleh beberapa pihak yaitu, calon pemasok, pemasok, user dari Departemen Procurement dan Departemen Material serta Admin. Admin bertugas mengelola aplikasi e-procurement dan mengelola database yang ada.

Ketiga, setelah melakukan analisis manfaat dan biaya, dapat dilihat bahwa penerapan $e$ procurement bagi PT Indesso dapat memberikan keuntungan. Hal ini dapat dilihat dari ketiga indikator, yaitu ROI, NPV dan IRR. Untuk ROI, tingkat pengembalian dari investasi untuk proyek pengembangan e-procurement mencapai angka 30,94\% yang menunjukan bahwa tingkat pengembalian untuk investasi e-procurement ini cukup bagus. NPV yang didapat juga mencapai nilai positif, dimana nilai positif menunjukan signal yang baik bagi perusahaan untuk melanjutkan penerapan e-procurement. IRR dari perhitungan yang didapat juga mencapai angka 0,309. Sehingga dari tiga perhitungan di atas, dapat disimpulkan bahwa dengan adanya aplikasi e-procurement tersebut, dapat meningkatkan customer value bagi pemasok dari PT Indesso Aroma. Terima kasih kepada saudari Nana Yuliani yang sudah berkontribusi dalam penelitian ini. 


\section{DAFTAR PUSTAKA}

Block, S. B., Hirt, G. A., Danielsen, B. R. (2009). Foundations of Financial Management, (13 ${ }^{\text {th }}$ ed.). New York: McGraw-Hill/Irwin.

Gitman, Lawrence J. (2006). Principle of Managerial Finance, $\left(11^{\text {th }}\right.$ ed.). New York: PearsonAddison Wesley.

Kalakota, Ravi \& Robinson. Marcia. (2001). E-business 2.0: Roadmap for Success. Boston: AddisonWesley.

Remenyi, D., Bannister, F., Money, A. (2007). The Effective Measurement and Management of ICT Cost \& Benefit, ( $3^{\text {rd }}$ ed.). Oxford: Elsevier.

Whitten, J. L., Bentley, L. D., Ditmann, K. C. (2001). System Analysis and Design Method, (5th ed.). London: Prentice Hall. 